\title{
$\mathrm{Fe}-14 \mathrm{Cr}$ 계 페라이틱 산화물 분산 강화강의 고온 압축 및 크리프 특성에 미치는 열처리의 영향

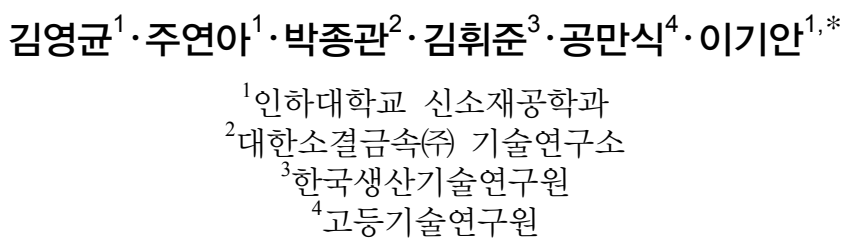

\section{Effect of Heat-Treatment on the Elevated Temperature Compression and Compressive Creep Properties of Fe-14Cr Ferritic Oxide Dispension Strengthened (ODS) Steel}

\author{
Young-Kyun Kim¹, Yeun-Ah Joo', Jong-Kwan Park², Hwi-Jun Kim³ , Man-Sik Kong ${ }^{4}$, \\ and Kee-Ahn Lee ${ }^{1, *}$ \\ ${ }^{I}$ Department of Materials Science and Engineering, Inha University, Incheon 22212, Republic of Korea \\ ${ }^{2} R \& D$ Center, Korea Sintered Metal Co., Ltd., Daegu 42983, Republic of Korea \\ ${ }^{3}$ Korea Institute of Industrial Technology, Incheon 21999, Republic of Korea \\ ${ }^{4}$ Institute for Advanced Engineering, Yongin 17180, Republic of Korea
}

\begin{abstract}
This study investigated the microstructure and the ambient-elevated temperature compression and elevated temperature creep properties of $\mathrm{Fe}-14 \mathrm{Cr}$ ferritic ODS steel manufactured by mechanical alloying (high energy ball milling) and hot extrusion processes. Initial microstructural observation of the as-extruded material identified elongated grains in the direction of extrusion; however, some recrystallization and grain growth were observed in the heat-treated material. The average grain sizes of the as-extruded material and heat-treated material were 0.4 and $1.1 \mu \mathrm{m}$, respectively. In addition, the heat treatment resulted in the increase in number density and the decrease in size of the nanocluster. A room temperature compression tests confirmed the heat-treated materials $(1457 \mathrm{MPa})$ had relatively higher yield than the as-extruded material $(1377 \mathrm{MPa})$, and a general tendency was observed that the difference in yield strength decreased as temperature increased. Furthermore, elevated temperature compressive creep tests confirmed that the heat-treated material had relatively greater creep resistance compared to the as-extruded material at all stress levels.
\end{abstract}

(Received July 14, 2017; Accepted September 18, 2017)

Keywords: mechanical alloying, oxide dispersion strengthening, microstructure, high temperature compression, high temperature creep

\section{1. 서 론}

$\mathrm{Fe}-14 \mathrm{Cr}$ 계 페라이틱(ferritic) 산화물 분산 강화(oxide dispersion strengthened, ODS)강은 $\alpha-\mathrm{Fe}$ 기지에 수 수십 나 노미터 크기의 산화물 입자가 높은 개수 밀도로 분산된 소재 로 중성자 조사 손상 저항성 및 고온 크리프 저항성이 뛰어나 다. 이에 따라 4세대 원자로(generation IV) 및 핵 융합로

* Corresponding Author: Kee-Ahn Lee

[Tel: +82-32-860-7532, E-mail: keeahn@inha.ac.kr]

Copyright (c) The Korean Institute of Metals and Materials (fusion reactor)의 구조 재료로 관심 받고 있다 [1-3]. 또한, 고 온에서의 기계적 특성이 우수하고 부식, 산화 저항성 그리고 내열성이 뛰어나 내구 한계 향상이 요구되는 엔진, 가스터빈 의 부품 등 내열 구조 재료 분야에서도 적용 가능성이 대두되 고 있다. 이와 함께 내마모 특성 역시 우수한 것으로 알려져 있어 핵 연료 피복관 외 상용 분야로의 적용 확대가 기대되고 있는 상황이다 [4].

방산 및 일반 산업에서 관심 받고 있는 ODS강이 뛰어난 물리, 화학적 특성을 보이는 이유는 기계적 합금화 중 분리 - 
분산된 $\mathrm{Y}_{2} \mathrm{O}_{3}$ 입자와 고화 과정에서 형성되는 Y-Ti-O 복합 산화물에 의한 것으로 보고되고 있다 $[5,6]$. 이러한 산화물들 은 열적, 기계적으로 매우 안정하며 고온 분위기에서 전위와 결정립계의 움직임을 고착시킨다. 또한, 매우 미세한 산화물 입자는 기지와 정합 상태로써 불일치 변형(misfit strain)을 낮 춰 고온에서 안정하게 유지되고 중성자 조사에 의한 헬륨 취 화와 공공 팽윤 저항성 역시 높이는 것으로 알려져 있다 [7,8]. 즉, 뛰어난 특성을 부여하는 산화물 입자의 분산은 ODS강의 제조에 가장 중요한 부분으로 인식되고 있다.

한편, $\mathrm{ODS}$ 강은 공정 변수에 따라 특성이 좌우되며 제조 공정이 매우 까다로워 구조용 소재로의 적용에는 한계점이 있다. 그 중 ODS강에 뛰어난 특성을 부여하는 $\mathrm{Y}_{2} \mathrm{O}_{3}$ 와 같은 산화물 입자를 소재 내부에 높은 개수 밀도로 고르게 분산시 키는 것은 매우 어려운 과정이며 이에 따라 기계적 합금화 단 계는 필수적이다. 그러나, ODS강 제조에 가장 중요한 과정 인 만큼 기계적 합금화의 최적화는 매우 어렵고 이에 따라 다 양한 시도들이 진행중에 있다. 특히, 높은 에너지를 부가하여 산화물을 고르게 분산 시키기 위해 최근 들어 $-150{ }^{\circ} \mathrm{C}$ 와 같은 극 저온에서 밀링(milling)을 수행하는 경우도 있다 [9-11]. 또한, 여러 밀링 공정을 복합하여 특성을 향상시키고자 하는 노력 역시 진행 중에 있다 [12]. 하지만, 기계적 합금화 공정 의 개선 시도에도 불구하고 현실적으로 제조 비용 상승에 대 한 문제점이 대두되고 있어 단순히 상온 밀링 공정 조건을 변 화시켜 $\mathrm{ODS}$ 강을 제조하고 특성을 향상시키는 것이 가장 중 요한 것으로 고려되고 있다.

이에 따라 상온 밀링 공정 변수의 제어와 열간 압출만을 이 용하여 ODS강을 제조하고 상온 및 고온 기계적 특성을 평가 하여 일반적으로 사용되는 ODS강과 그 특성을 비교해볼 필 요가 있다. 이와 함께 ODS강에서 가장 중요한 크리프 특성 에 대한 연구는 필수적으로 수행되어야 한다. 또한, ODS강 의 조직 안정화, 인성 및 기계적 특성을 향상시키기 위한 열 처리에 대한 연구가 필요하다. 그러나, 열처리를 수행하고 상 온 및 고온에서의 기계적 특성과 크리프 특성을 종합적으로 연구한 결과는 미비한 실정이다.

따라서 본 연구에서는 상온 밀링 공정과 열간 압출을 통해 $\mathrm{Fe}-14 \mathrm{Cr}$ 페라이틱 $\mathrm{ODS}$ 강을 제조하고 이와 함께 $1100{ }^{\circ} \mathrm{C}$ 에 서 열처리를 수행하였다. 이와 함께 열처리 전, 후 소재에 대 한 미세조직과 상온 및 고온에서의 기계적 특성, 크리프 특성 을 조사하고 이에 대한 변형 거동을 규명하고자 하였다.

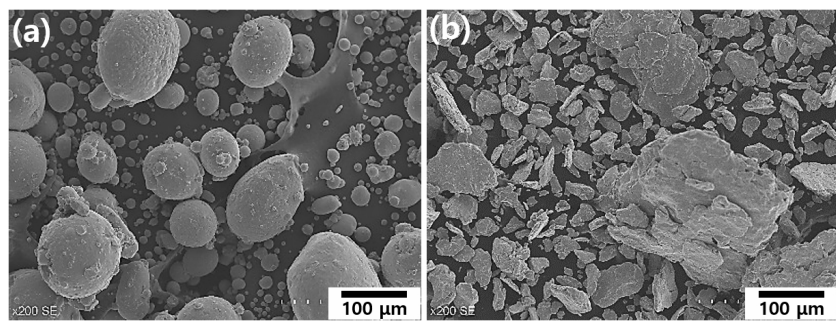

Fig. 1. SEM micrographs illustrating morphologies of (a) initial powders and (b) high energy ball milled powders.

\section{2. 실험 방법}

그림 1 (a)는 이번 연구에 사용된 Fe-14Cr-2W-0.3Ti(wt\%) 원료 분말로 입도 분포는 $30 \sim 100 \mu \mathrm{m}$ 수준으로 나타났다. 상기 분말에 $20 \sim 50 \mathrm{~nm}$ 크기의 $\mathrm{Y}_{2} \mathrm{O}_{3}$ 분말 입자를 $0.5 \mathrm{wt} \%$ 함께 첨가, 혼합한 뒤 기계적 합금화(mechanical alloying)를 실시하였다. 기계적 합금화는 Simoloyer CM01(ZOZ 사) 장 비를 이용하여 high energy ball milling 을 수행하였으며 이 때 아르곤 분위기하에서 볼배합비(ball to powder weight ratio, BPR) 10:1 조건으로 8시간 반복 실시하였다. 그림 1 (b) 와 같은 feedstock을 얻을 수 있었다. 기계적 합금화된 feedstock은 캔에 충진하여 $400{ }^{\circ} \mathrm{C}$ 의 온도에서 $6 \times 10^{-7}$ torr의 진공 수준을 만든 후 5 시간 동안 탈 가스 작업을 하였다. 이 후 $1150{ }^{\circ} \mathrm{C}$ 에서 7:1의 압출비로 열간 압출을 통해 약 2370 $\mathrm{mm}$ 의 길이를 갖는 $\mathrm{ODS}$ 강의 봉재를 제조하였다. 이와 함께 열처리에 따른 미세조직 및 특성 변화를 알아보고자 $1100{ }^{\circ} \mathrm{C}$ 진공 분위기에서 1 시간 가량 열처리를 수행하였다.

ODS강의 열처리에 따른 상 변화를 알아보고자 X-ray 회 절 분석기(X-ray diffractometer, XRD, Ultima IV)를 이용하 였다. 열처리, 전 후 소재의 미세조직 관찰을 위해 탄화 규소 마모지(\#100 \#2000) 및 $1 \mu \mathrm{m}$ 다이아몬드 현탁액(suspension) 을 이용하여 기계적 연마를 수행하였다. 이와 함께 $0.01 \mu \mathrm{m}$ 의 교질 이산화규소(colloidal silica)를 사용하여 미세 연마한 후 step size $60 \mathrm{~nm}, 15 \mathrm{kV}$ 의 조건하에서 후방산란전자회절 (electron backscatter diffraction, EBSD) 관찰을 수행하였다. 여기서 EBSD data 분석은 orientation image microscopy (OIM, TexSEM)를 이용하여 분석하였다. 또한, ODS강에 존 재하는 나노 크기의 산화물 클러스터(oxide cluster)를 관찰 하기 위해 $\Phi 3 \mathrm{~mm}$ 의 디스크 형태로 시편을 절단 후 기계적 연마를 통해 $150 \mu \mathrm{m}$ 두께의 얇은 박막을 제작하였다. 이와 함께 딤플링(dimpling)을 통해 $20 \mu \mathrm{m}$ 두께로 연마 후 이온 밀 링(ion milling)법을 이용하여 마지막 thinning을 진행한 뒤 
Table 1. 2-Theta locations and FWHM of as-extruded and heat-treated specimens.

\begin{tabular}{c|c|cccc}
\hline 2-Theta $\left[^{\circ}\right]$ & Powder & 44.260 & 64.437 & 81.500 & 97.885 \\
\cline { 2 - 6 } & As-extruded & 44.572 & 64.992 & 82.148 & 98.663 \\
\cline { 2 - 6 } & Heat-treated & 44.528 & 64.753 & 82.104 & 98.557 \\
\hline \multirow{2}{*}{ FWHM $\left[^{\circ}\right]$} & As-extruded & 0.61 & 0.83 & 0.91 & 0.73 \\
\cline { 2 - 6 } & Heat-treated & 0.56 & 0.79 & 0.84 & 0.797 \\
\hline
\end{tabular}

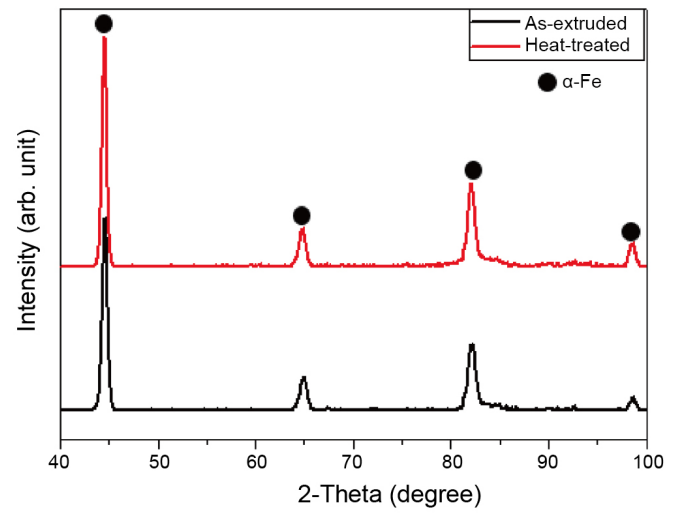

Fig. 2. X-ray diffraction analysis results of an as-extruded specimen and heat-treated specimen.

주사투과전자현미경(scanning transmission electron microscopy, STEM, HF-3300) 관찰을 수행하였다.

제조된 두 ODS강의 상온 및 고온에서의 기계적 특성을 평 가하기 위해 상온 $900{ }^{\circ} \mathrm{C}$ 까지의 경도를 측정하였다. 이와 함 께 지름 $4 \mathrm{~mm}$ 높이 $6 \mathrm{~mm}$ 크기의 원통형 압축 시편을 가공하 여 상온 및 고온 압축 시험을 수행하였다. 여기서 압축 시험은 상온, $500,650,700$ 그리고 $900{ }^{\circ} \mathrm{C}$ 의 온도 조건에서 수행하였 으며 초기 변형률 속도 $1 \times 10^{-3} / \mathrm{s}$ 로 각각 최종 변형률(total strain, $\varepsilon_{t}$ ) 0.6 까지 진행하였다. 또한, 고온 크리프 특성을 알아 보고자 세 변의 길이가 각각 $3,3,6 \mathrm{~mm}$ 의 직육면체 시편을 가 공 후 $\mathrm{ODS}$ 강의 가용 온도인 $650{ }^{\circ} \mathrm{C}$ 에서 크리프 시험을 진행 하였다. 고온 압축 크리프 시 하중은 정부하형(constant load type)으로 $650{ }^{\circ} \mathrm{C}$ 항복 강도 이하의 응력 범위 $(120 \sim 270 \mathrm{MPa})$ 를 만족하도록 설정하였으며, $0.001 \mathrm{~mm}$ 까지 변화를 감지할 수 있는 신장계(extensometer)를 이용하여 시간에 따른 시편 의 변위를 측정하였다. 시간, 하중, 온도 그리고 변위 데이터는 신장계와 크리프 장비가 연결된 컴퓨터의 데이터 수집 소프트 웨어를 이용하여 연속적으로 수집하였다.

\section{3. 실험결과 및 고찰}

\section{1 $\mathrm{Fe}-14 \mathrm{Cr}$ 계 $\mathrm{ODS}$ 강의 미세조직 관찰 결과}
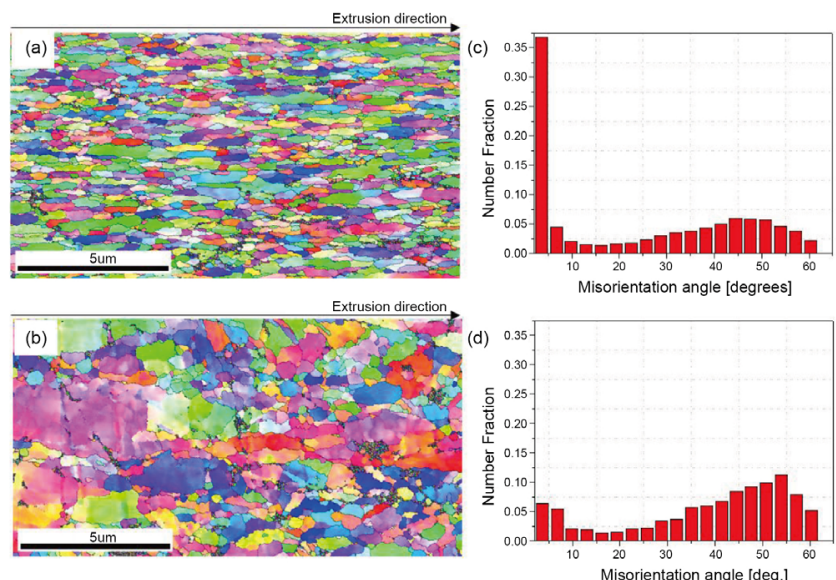

Fig. 3. EBSD inverse pole figure maps of (a) as-extruded specimen, (b) heat-treated specimen, and misorientation angle distributions of (c) as-extruded specimen and (d) heat-treated specimen.

그림 2는 열처리 전, 후 ODS강의 X 선 회절 분석 결과이며 얻어진 XRD 결과로부터 2-theta와 반치전폭(full width of half maximum)을 구하여 표 1에 나타냈다. 먼저, as-extruded 및 heat-treated 소재 모두 $\alpha-\mathrm{Fe}$ 상 만이 검출되었으며 첨가된 $\mathrm{Y}_{2} \mathrm{O}_{3}$ 피크는 쉽게 나타나지 않았다. 그러나, as-extruded 소 재에 비해 heat-treated 소재에서 피크 강도가 낮게 검출되었 고 이와 함께 피크 broadening 현상이 줄어드는 것을 알 수 있 었다. 이를 FWHM 값으로 비교해 본 결과, 상대적으로 높은 피크 강도를 갖는 heat-treated 소재가 $97.885^{\circ}$ 를 제외한 모든 피크들에서 상대적으로 낮은 FWHM 값을 나타내고 피크의 모양 역시 날카로워지는 것으로 나타났다. 이러한 피크 모양 의 변화는 심한 소성 변형이 가해질 경우 나타나는 것으로써 산화물의 분해(dissolution of oxides), 비정질화 (amorphization) 그리고 격자 뒤틀림(lattice distortion)에 의 한 것으로 판단된다 $[13,14] . \mathrm{MA}$ 와 열간 압출 과정에서 소재 는 심한 소성 변형을 받고 이에 따라 피크 broadening 현상이 일어날 수 있다. 그러나 열처리 과정에서 일부 미세조직적 변 화가 발생하며 이에 따라 격자 뒤틀림이 완화되는 것으로 유 추해볼 수 있었다.

이러한 미세조직적 변화를 알아보고자 EBSD 분석을 수행 하였으며 이를 그림 3에 도시하였다. 먼저 그림 $3(\mathrm{a}, \mathrm{c})$ 에 나 타낸 inverse pole figure map 관찰 결과, as-extruded 소재의 경우 압출 방향으로 결정립들이 일부 연신된 형태를 나타낸 반면 heat-treated 소재는 이러한 경향이 줄어드는 것을 알 수 있었다. 또한, 평균 결정립 크기를 측정해본 결과, as-extruded 소재는 $0.41 \mu \mathrm{m}$, heat-treated 소재는 $1.12 \mu \mathrm{m}$ 로 
(a)

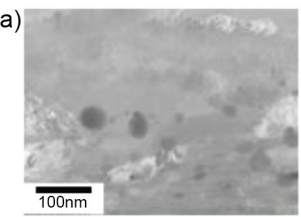

(b)

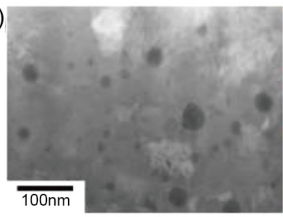

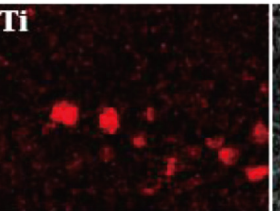
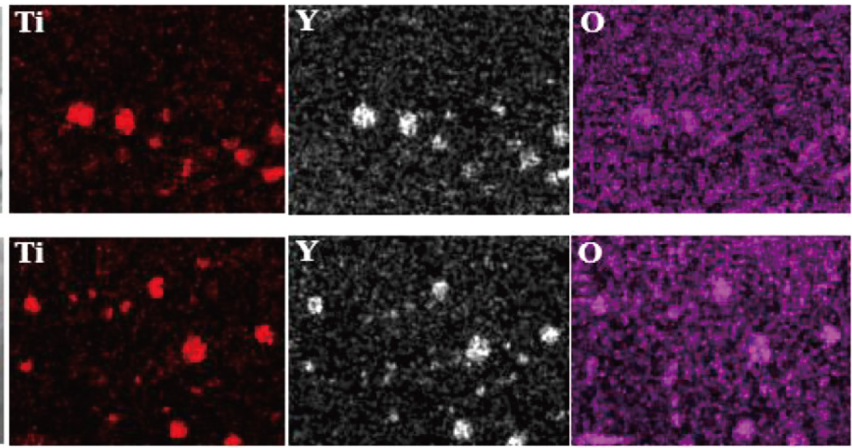

Fig. 4. STEM-EDS mapping images of (a) as-extruded and (b) heat-treated specimens.

확인되었다. 이와 함께 misorientation angle distribution을 분 석해본 결과(그림 $3(\mathrm{~b}, \mathrm{~d}))$, as-extruded 소재는 저각경계(low angle boundary, LAB) 분률이 지배적인 경향을 보였으나 heat-treated 소재에서는 $\mathrm{LAB}$ 분률이 급격히 줄어든 것을 알 수 있었다. 즉, inverse pole figure map과 misorientation angle distribution 분석을 통해 열처리 중 일부 재결정 및 결정립 성 장이 발생한다는 것을 유추해볼 수 있었다. 그러나, 여기서 주목해야할 점은 일반적인 페라이틱 강과 비교했을 때 재결 정의 정도는 매우 차이가 나타난다는 것이다. 일반적으로 페 라이틱 강의 정적 재결정 온도는 약 $800{ }^{\circ} \mathrm{C}$ 수준으로 보고되 고 있으며 MA 및 열간 압출을 통해 심한 변형을 가하는 소재 의 경우 그 온도 범위는 낮아지는 것으로 알려져 있다 [15]. 반면, ODS강의 경우 나노 크기의 산화물 입자들(ex. $\mathrm{T}_{2} \mathrm{Ti}_{2} \mathrm{O}_{7}, \mathrm{Y}_{2} \mathrm{TiO}_{5}$, etc.)이 결정립계 및 내부에 존재함에 따라 재결정 및 결정립 성장을 방해하는 것으로 보고되고 있다 $[16,17]$. 즉, $1100{ }^{\circ} \mathrm{C}$ 에서 열처리를 수행했음에도 불구하고 그림 3 (c)와 같이 평균 $1 \mu \mathrm{m}$ 수준의 결정립이 관찰되는 것은 나노 크기의 산화물 입자들이 입계 및 입내에 높은 개수 밀도 로 고르게 분산되어 있다고 추론할 수 있다.

한편, 두 소재 내부에 존재하는 나노 클러스터(nano cluster)를 확인하고자 에너지분산형 X-ray 분광분석(energy dispersive X-ray spectroscopy, EDS)을 수행했으며 이를 그 림 4에 도시하였다. 여기서 (a)는 as-extruded 소재, (b)는 heat-treated 소재이다. STEM 이미지 관찰 결과, 두 소재 모 두 첨가한 $\mathrm{Y}_{2} \mathrm{O}_{3}$ 형태가 아닌 $\mathrm{Y}-\mathrm{Ti}-\mathrm{O}$ 나노 클러스터를 형성 시키는 것으로 나타났다. C. L. Fu 등[18]은 고화 과정에서 공 공(vacancy, $\mathrm{V}$ )와 침입형 산소 원자(interstitial oxygen atom, $\mathrm{O}$ )가 결합하여 쌍(pair)를 형성시키고 이러한 V-O pair는 산 화 친화도가 높은 $\mathrm{Y}, \mathrm{Ti}$ 와 재 결합하여 $\mathrm{Y}-\mathrm{Ti}-\mathrm{O}$ 나노 클러스 터를 생성하는 것으로 보고 한 바 있다. 즉, $\mathrm{ODS}$ 강에서 $\mathrm{Y}_{2} \mathrm{O}_{3}$ 가 Y-Ti-O 나노 클러스터로 변화하는 것에 대한 원인은 아직

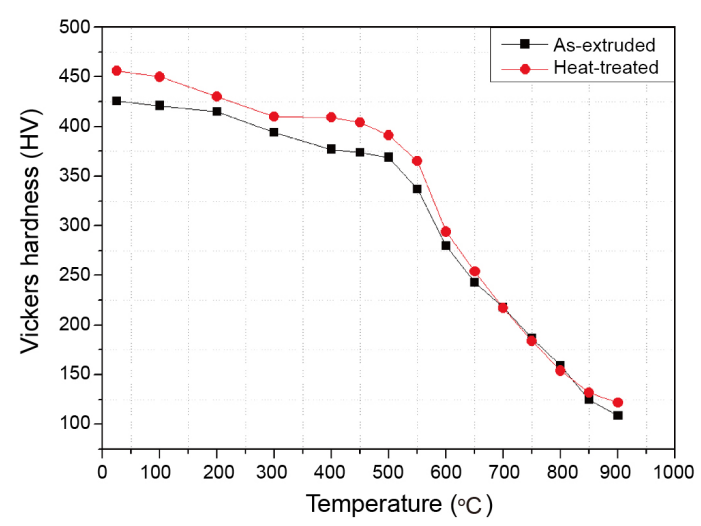

Fig. 5. Vickers hardness results at various temperatures.

명확히 규명되지 않았지만 미세조직학적 변화에 대해서는 확인되어 왔다. 이와 함께, Y-Ti-O 나노 클러스터는 ODS강 의 특성에 매우 중요한 역할을 하는 것으로 알려져 있어 이에 대한 상 분석 연구들이 다양하게 보고되고 있다. M. C. Brandes 등[19] 및 $\mathrm{Y} . \mathrm{Wu}$ 등[20]은 고분해능(high resolution) 투과전자현미경(transmission electron microscopy, TEM), 원 자탐침단층촬영(atom probe tomography, APT)를 통해 cubic 구조를 갖는 $\mathrm{Y}_{2} \mathrm{Ti}_{2} \mathrm{O}_{7}$ 혹은 hexagonal 또는 orthorhombic 구 조를 갖는 $\mathrm{Y}_{2} \mathrm{TiO}_{5}$ 임을 밝힌 바 있다. 또한, 동일한 결과들이 여러 다른 연구에서도 보고되고 있어 그림 4에 나타난 나노 클러스터들 역시 $\mathrm{Y}_{2} \mathrm{Ti}_{2} \mathrm{O}_{7}$ 및 $\mathrm{Y}_{2} \mathrm{TiO}_{5}$ 임을 유추해볼 수 있었다.

$\mathrm{Y}-\mathrm{Ti}-\mathrm{O}$ 나노 클러스터들의 평균 크기를 측정해 본 결과 as-extruded 소재에서는 약 $33.32 \mathrm{~nm}$, heat-treated 소재에서 는 약 $24.68 \mathrm{~nm}$ 인 것으로 확인되어 열처리에 따라 나노 클러 스터들의 크기가 감소하는 경향을 보였다. 이와 함께 반복된 실험을 통하여 Y-Ti-O 나노 클러스터의 개수 밀도 역시 heat-treated 소재에서 상대적으로 더 높다는 것을 확인할 수 있었다. 
Table 2. Yield strength(YS) at various temperatures of as-extruded and heat-treated specimens.

\begin{tabular}{c|cc}
\hline & As-extruded YS [MPa] & Heat-treated YS [MPa] \\
\hline $25{ }^{\circ} \mathrm{C}$ & 1377.6 & 1457.9 \\
\hline $500{ }^{\circ} \mathrm{C}$ & 1070.8 & 1074.4 \\
\hline $700{ }^{\circ} \mathrm{C}$ & 340.1 & 343.6 \\
\hline $900{ }^{\circ} \mathrm{C}$ & 223.1 & 219.8 \\
\hline
\end{tabular}
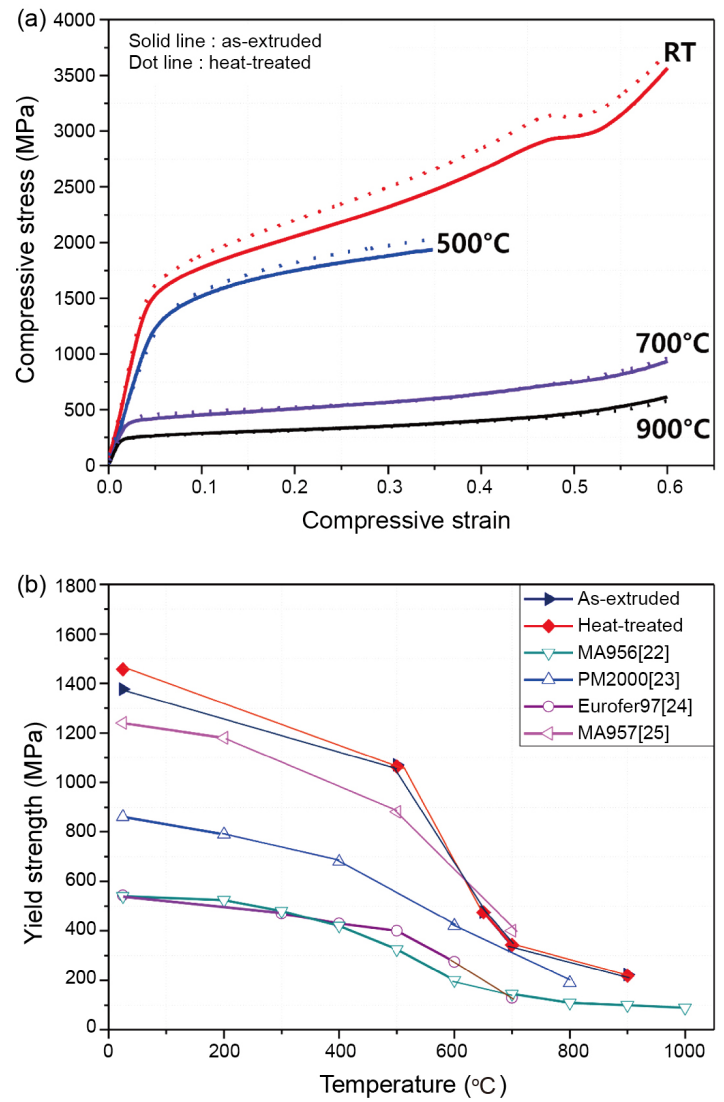

Fig. 6. (a) Compressive stress-strain curves at various temperatures and (b) yield strength comparison with other ODS steels at various temperatures for a nominal strain rate of $10^{-3} \mathrm{~s}^{-1}$.

\section{2 $\mathrm{Fe}-14 \mathrm{Cr}$ 계 ODS강의 상, 고온 경도 및 고온 압축 특성}

본 연구에 사용된 두 $\mathrm{ODS}$ 강에 대하여 상온 $~ 900{ }^{\circ} \mathrm{C}$ 까지 연속적으로 변화하는 경도 값을 측정했으며 그 결과를 그림 5 에 도시하였다. 먼저, 경도 변화 곡선들을 살펴보면 두 소재 모두 약 $500{ }^{\circ} \mathrm{C}$ 에서부터 경도 감소 폭이 증가하는 것으로 나 타나며 두 소재에서의 거동 차이는 크게 확인되지 않았다. 이 와 함께 경도 변화 곡선들에서 주목할 만 한 점은 heat-treated 소재가 as-extruded 소재에 비해 약 $650{ }^{\circ} \mathrm{C}$ 까지 상대적으로 우수한 경도 값을 나타낸다는 것이다. 대개 열처리에 따라 경 도는 감소하는 것이 일반적이며 앞선 미세조직 관찰에서 확
인한 바와 같이 재결정 및 일부 결정립 성장이 발생한 소재가 높은 경도를 보이는 것은 흥미로운 결과이다. 이러한 원인은 열처리에 따라 나노 cluster들의 개수 밀도 및 그 크기가 변화 했기 때문으로 판단되며 그 결과 일부 결정립 성장이 발생하 고 $\mathrm{LAB}$ 분률이 감소 했음에도 heat-treated 소재의 경도가 높 은 것으로 사료된다.

경도와 같이 국부적인 영역의 기계적 특성이 아닌 소재의 거시적인 기계적 특성을 알아보고자 상온 $900{ }^{\circ} \mathrm{C}$ 압축 시 험을 수행했으며 이를 그림 6 (a)에 도시하였다. 얻어진 as-extruded 및 heat-treated 소재들의 각 온도에 대한 항복 강 도를 표 2에 나타내었다. 상온 압축 시험 결과 열처리 후 항복 강도가 대부분의 조건에서 높게 얻어졌으며 $500{ }^{\circ} \mathrm{C}$ 이상의 온도에서는 그 차이가 거의 없는 것으로 확인되었다. 이러한 경향은 그림 5 의 온도에 따른 경도 측정 결과와도 잘 일치하 는 것이다. 일반적으로 강화 기구 중 결정립 미세화에 의한 Hall-Petch 강화와 전위 밀도 차이에 의한 강화 영향이 열처 리를 수행함에 따라 줄어들 것을 고려해 보면 상기 결과는 분 산상 장애물에 의한 강화(dispersed barrier hardening)의 영향 이 우세하게 작용하여 나타나는 것으로 판단된다.

한편 그림 6 (a)의 온도별 압축 곡선을 자세히 살펴보면 낮 은 온도인 상온에서는 최종 변형률까지 파단이 일어나지 않 았음에도 불구하고 $500{ }^{\circ} \mathrm{C}$ 온도에서는 as-extruded 와 heattreated 두 조건 모두에서 0.3 의 변형률에 파단이 일어남을 알 수 있다. 이와 관련하여 압축 시험 후 거시적 시편 표면 관 찰 결과에서 $500{ }^{\circ} \mathrm{C}$ 시편들에서만 푸른색의 산화막이 관찰 되었다. 즉 본 연구의 $500{ }^{\circ} \mathrm{C}$ 압축 시험에서 나타나는 취성 특성은 ferrite phase가 Cr-enriched $\alpha$ phase로 변화하는 500 ${ }^{\circ} \mathrm{C}$ 부근의 청열 취성 때문으로 추론된다 [21]. 또한, 압축 시 험 후 표면에서 푸른 색의 산화막이 형성된 것으로 나타나 청 열 취성 역시 $500{ }^{\circ} \mathrm{C}$ 압축 시험에서 취성 파괴를 나타낸 것으 로 생각된다 [21].

두 소재의 항복 강도 수준을 알아보고자 현재까지 보고되 고 있는 페라이틱 ODS강과 비교하고 이를 그림 6 (b)에 나타 냈다. 그 결과, 모든 온도 범위에서 MA 956 [22], PM 2000 [23] and Eurofer97 [24]보다 뛰어난 항복 강도를 나타냈으며 MA957 [25]과 유사한 고온 항복 강도를 나타냈다. 즉, 본 연 구에서 제조된 두 소재 모두 상온 밀링 공정과 열간 압출만 수행했음에도 불구하고 뛰어난 고온 기계적 특성을 갖는 것 으로 확인되었다.

그림 7은 압축 시험 후 표면을 관찰한 결과로써 (a)는 as-extruded, (b)는 heat-treated 소재이다. 먼저 상온의 경우 두 
(a)
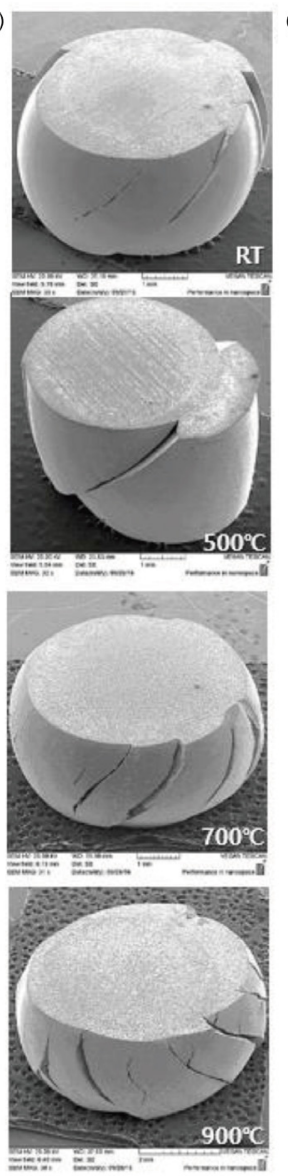

Fig. 7. Macro images of (a) as-extruded and (b) heat-treated specimens after compression tests with various temperatures.

소재 모두 가해지는 하중의 $45^{\circ}$ 방향으로 전단균열(shear crack)이 형성되었으며 표면에서의 큰 차이점은 확인되지 않 았다. 반면, 취성 파괴를 나타낸 $500{ }^{\circ} \mathrm{C}$ 압축 시편의 표면에서 는 primary 전단 균열 외 상온 에서와 같이 secondary 균열은 거의 형성되지 않았다. 또한, 상온의 경우 조대한 균열에서 일 부 굴곡진 형태의 균열이 생성되었지만 $500{ }^{\circ} \mathrm{C}$ 압축 시편의 경 우 매우 날카로운 균열을 나타냈다. $700{ }^{\circ} \mathrm{C}$ 압축 시편의 경우 변형을 수용하는 과정에서 상온과 동일한 최종 변형률을 부여 했음에도 불구하고 전단 균열이 굴곡진 형태를 보여 파괴 거 동이 상당히 다른 것을 알 수 있었다. 마지막으로 $900{ }^{\circ} \mathrm{C}$ 시편 의 경우 전단 균열과 함께 하중이 가해지는 방향으로 균열이 형성되었다. 이러한 원인은 고온에서 생성되는 oxide scale에 의한 것으로 판단되며 표면 고 배율 관찰 결과 수직 균열(하중 이 가해지는 방향)을 따라 oxide scale이 나타나는 것을 알 수 있었다.
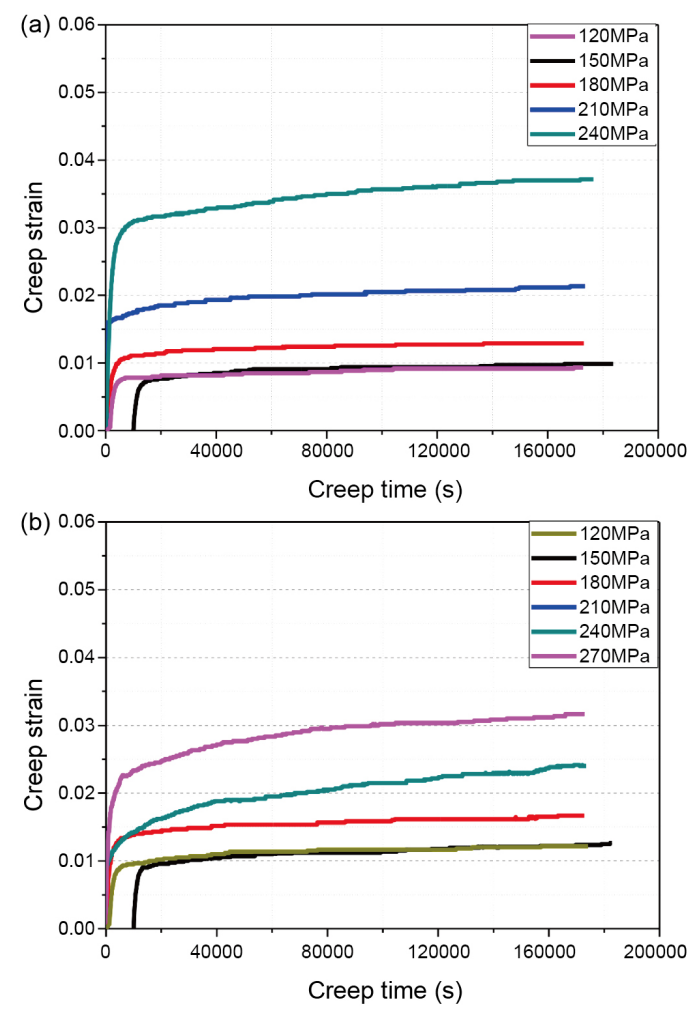

Fig. 8. Compressive creep curves of (a) as-extruded specimen and (b) heat-treated specimen at $650{ }^{\circ} \mathrm{C}$.

\subsection{ODS강의 고온 압축 크리프 특성}

인장 크리프 시편으로 제작하기에 부적합한 분말 야금 소 재나 코팅층 등의 작은 시편만 얻어지는 경우 크리프 특성 평 가가 제한적이기 때문에 압축 크리프 시험을 수행할 수 있다 [26,27]. 본 연구에서는 여러 응력 조건(120 270 MPa)에서 두 소재에 대해 $650{ }^{\circ} \mathrm{C}$ 압축 크리프 시험을 수행하고 시간 (time)에 대한 크리프 변형 곡선들을 그림 8에 도시하였다. 여기서 (a)는 as-extruded, (b)는 heat-treated 소재이며 두 소 재 모두 $120 \mathrm{MPa}, 150 \mathrm{MPa}$ 조건에서 크리프 곡선이 중첩되 어 이를 구분하고자 $150 \mathrm{MPa}$ 의 크리프 곡선을 $10000 \mathrm{~s}$ 이동 하여 도시하였다. 이와 함께 크리프 시험에 앞서 $650{ }^{\circ} \mathrm{C}$ 압축 항복 강도를 측정해 본 결과, 동일한 $475 \mathrm{MPa}$ 을 나타냈다. 그림 8 을 살펴보면 tertiary 크리프를 제외하고 dislocation hardening에 기인하는 primary 크리프, hardening과 restoration의 dynamic balance에 의한 secondary 크리프 거동 이 확인되었다. 또한, 부가 응력 증가에 따라 primary 크리프 의 종점인 천이 크리프 변형 한계점 $\left(\varepsilon_{t}\right)$ 이 증가하는 경향을 보 였다. 한편, heat-treated 소재가 모든 응력 범위에서 as-extruded 소재보다 상대적으로 낮은 크리프 변형을 나타 


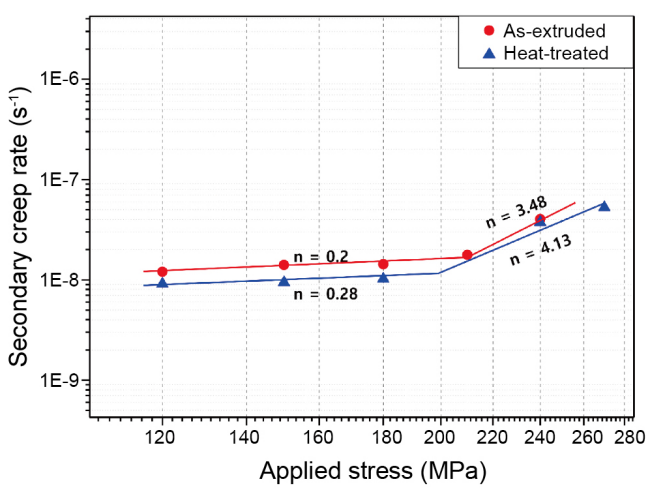

Fig. 9. Stress dependence of the secondary creep rate of the as-extruded and heat-treated specimens.

냈다. 즉, 열처리에 따라 $650{ }^{\circ} \mathrm{C}$ 압축 크리프 저항성이 증가 한다는 것을 알 수 있었다. 이는 앞선 미세조직에서 확인한 바와 같이 열처리 후 산화물의 밀도가 증가하고 그 크기가 감 소하였기 때문으로 사료된다.

그림 8 (a) 결과를 바탕으로 Dorn과 Garofalo 등이 제시한 아래의 식을 이용하여 크리프 시간-변형의 관계에 대해 해석 할 수 있다 $[28,29]$.

$$
\varepsilon=\varepsilon_{0}+\varepsilon_{t}\left(1-e^{-r t}\right)+\dot{\varepsilon}_{s s} t
$$

여기서 $\varepsilon_{0}$ 은 instantaneous strain, $r$ 은 transient creep rate와 transient creep strain의 비율, $\varepsilon_{t}$ 은 total transient strain, $\varepsilon_{s s}$ 은 steady-state creep rate 그리고 t는 시간을 나타낸다. 이를 통하 여 크리프 특성을 정량화 시킬 수 있는 secondary 크리프 속도 를 구할 수 있으며 그 결과를 그림 9에 나타내었다. 그림에 알 수 있듯이 heat-treated 소재가 as-extruded 소재 비해 상대적으 로 뛰어난 크리프 저항성을 갖는 것을 정량적으로 확인해볼 수 있었다. 한편, 응력에 대한 secondary 크리프 속도의 의존성을 나타내는 stress exponent(n)의 경우 낮은 응력에서 as-extruded 및 heat-treated의 경우 $\mathrm{n}=0.2,0.28$ 로 각각 측정되었다. 그러 나, 상대적으로 높은 응력에서 as-extruded 및 heat-treated의 경 우 각각 $\mathrm{n}=3.48,4.13$ 으로 급격히 증가하는 경향을 보였다. 일 반적인 ODS강에서의 크리프 거동은 applied stress 증가에 따 라 diffusional flow $(\mathrm{n}<1)$, power law 크리프 $(\mathrm{n}=3 \sim 10)$ 그리고 power law breakdown(n > 20)로 크리프 기구가 변화한다 [30,31]. 이를 통해 낮은 응력 범위에서는 diffusional 크리프이 작동하며 상대적으로 고 응력에서는 power law 크리프 기구가 작동한다는 것을 유추해볼 수 있었다.
결과적으로 본 연구에서 제조된 $\mathrm{Fe}-14 \mathrm{Cr}$ 계 페라이틱 $\mathrm{ODS}$ 강은 상용 ODS강과 비교하여 유사하거나 혹은 뛰어난 수준 의 상온 및 고온 기계적 특성을 나타내었다. 이와 함께 열처 리에 따라 변화한 미세조직으로 인해 기계적 특성이 향상되 는 것으로 확인되었다.

\section{4. 결 론}

본 연구에서는 MA 및 열간 압출 공정을 통해 $\mathrm{Fe}-14 \mathrm{Cr}$ 페 라이틱 산화물 분산 강화 합금강을 제조하였다. 이와 함께 열 처리를 통해 조직을 안정화하고 미세조직 및 기계적 특성에 대해 조사했으며 아래와 같은 결론을 얻을 수 있었다.

미세조직 관찰 결과, as-extruded 소재의 경우 압출 방향으 로 결정립이 연신된 형태를 보인 반면 heat-treated 소재의 경 우 일부 재결정 및 결정립 성장이 발생하였다. 그러나, 일반 적인 페라이틱 강과 비교해볼 때 재결정 및 결정립 성장은 크 게 두드러지지 않은 것으로 확인되었으며 이와 함께 열처리 후 산화물이 개수 밀도가 증가하고 크기는 감소하는 것으로 나타났다.

상온 및 고온 경도 측정 결과, 모든 온도 범위에서 heat-treated 소재가 상대적으로 뛰어난 경도 값을 보였다. 이 러한 원인은 ODS강의 strengthening mechanism 중 nano cluster에 의한 dispersed barrier hardening에 기인한 것을 유 추해볼 수 있었다.

상온 압축 시험 결과, 경도 값과 같이 heat-treated 소재가 상대적으로 뛰어난 항복 강도를 보였다. 그러나, 경도에서와 는 달리 온도가 상승함에 따라 서로 유사한 기계적 특성을 보 이는 것으로 확인되었다. 한편, 두 소재 모두 온도 상승에 따 라 항복 강도가 감소하는 일반적인 경향을 보였으나 상용 ODS 강에 비해 뛰어난 특성을 보이는 것으로 나타났다.

고온 압축 크리프 시험 결과, heat-treated 소재가 모든 응 력 범위에서 상대적으로 뛰어난 크리프 저항성(secondary creep rate)을 보이는 것으로 확인되었다. 이와 함께 낮은 응 력 범위에서는 diffusional creep 기구가, 높은 응력 범위에서 는 dislocation creep 기구가 작동한다는 것을 알 수 있었다.

\section{감사의 글}

This research was supported by Republic of Korea's Ministry of Trade, Industry and Energy, Program for the Development of Core Defense Materials. 


\section{REFERENCES}

1. M. K. Miller, E. A. Kenik, K. F. Russell, L. Heatherly, D. T. Hoelzer, and P. J. Maziasz, Mater. Sci. Eng. A 353, 140 (2003).

2. M. J. Alinger, G. R. Odette, and D. T. Hoelzer, Acta Mater. 57, 392 (2009).

3. A. Hirata, T. Fujita, Y. R. Wen, J. H. Schneibel, C. T. Liu, and M. W. Chen, Nat. Mater. 23, 1 (2011).

4. J. H. Kim and J. H. Lee, J. Kor. Powd. Met. Inst. 20, 228 (2013).

5. V. V. Sagaradze, K. A. Kozlov, N. V. Kataeva, A. V. Litvinov, and V. A. Shabashov, Phys. Met. Metallogr. 113, 372 (2012).

6. L. Toualbi, M. Ratti, G. Andre, F. Onimus, and Y. de Carlan, J. Nucl. Mater. 417, 225 (2011).

7. S. Ukai and M. Fujiwara, J. Nucl. Mater. 307-311, 749 (2002).

8. R. Lindau, A. Moeslang, M. Schirra, P. Schlossmacher, and M. Klimenkov, J. Nucl. Mater. 307-311, 769 (2002).

9. J. H. Gwon, J. H. Kim, and K. A. Lee, J. Nucl. Mater. 459, 205 (2015).

10. J. H. Kim, T. S. Byun, D. T. Hoelzer, C. H. Park, J. T. Yeom, and J. K. Hong, Mater. Sci. Eng. A 559, 111 (2013).

11. J. H. Kim, T. S. Byun, J. H. Lee, J. Y. Min, S. W. Kim, C. H. Park, and B. H. Lee, J. Nucl. Mater. 449, 300 (2014).

12. J. B. Seol. K. M. Kim, and J. H. Kim, Korean J. Met. Mater. 54, 171 (2016).

13. V. V. Sagaradze, K. A. Kozlov, N. V. Kataeva, A. V. Litvinov, and V. A. Shabashov, Phys. Met. Metallogra. 113, 372 (2012).

14. L. Toualbi, M. Ratti, G. Andre, F. Onimus, and Y. D. Carlan, J. Nucl. Mater. 417, 225 (2011).

15. H. K. D. H. Bhadeshia, Mater. Sci. Eng. A 223, 64 (1997).

16. M. Dade, J. Malaplate, J. Garnier, F. D. Geuser, N.
Lochet, and A. Deschamps, J. Nucl. Mater. 472, 143 (2016).

17. T. Narita, S. Ukai, B. Leng, S. Ohtsuka, and T. Kaito, $J$. Nucl. Sci. Technol. 50, 314 (2013).

18. C. L. Fu, M. Krcmar, G. S. Painter, and X. Q. Chen, Phys. Rev. Lett. 99, 225502 (2007).

19. M.C. Brandes, L. Kovarik, M. K. Miller, and M. J. Mills, J. Mater. Sci. 47, 3913 (2012).

20. Y. Wu, J. Ciston, S. Kraemer, N. Bailey, G. R. Odette, and P. Hosemann, Acta Mater. 111, 108 (2016).

21. J. K. Sahu, U. Krupp, R. N. Ghosh, and H. J. Christ, Mater. Sci. Eng. A 508, 1 (2009).

22. M. S. El-Genk and J. M. Tournier, J. Nucl. Mater. 340, 93 (2005).

23. K. L. Klueh, J. P. Shingledecker, R. W. Swindeman, D. T. Hoelzer, J. Nucl. Mater. 341, 103 (2005).

24. A. Ramar, P. Spatig, and R. Schaublin, J. Nucl. Mater. 382, 210 (2008).

25. A. Alamo, V. Lambard, X. Averty, and M. H. Mathon, J. Nucl. Mater. 329-333, 333 (2004).

26. F. H. Froes and J. J. deBarbadillo, Structural Applications of Mechanical Alloying, ASM International Conference, Myrtle Beach, South Carolina, 27-29 March (1990).

27. S. K. Sondhi, B. F. Dyson, and M. McLean, Acta Mater. 52, 1761 (2004).

28. K. E. Amin, A. K. Mukherjee, and J. E. Dorn, J. Mech. Phys. Solids 18, 413 (1970).

29. G. A. Webster, A. P. D. Cox, and J. E. Dorn, Metal Sci. J. 3, 221 (1969).

30. J. RÖsler, R. Joos, and E. Arzt, Met. Trans. A 23A, 1521 (1992).

31. O.D. Sherby, G. Gonzalez-Doncel, and O.A. Ruano, Threshold stresses in particle-hardened materials, Creep and fracture of engineering materials and structures, J. C. Earthman and F. A. Mohamed (eds), TMS, 1997, pp. 9-18. 